\title{
Commentary: High-dose induction chemoradiation for lung cancer: The past is prologue
}

\author{
Nasser Altorki, MD, and Brendon Stiles, MD
}

\footnotetext{
From the Division of Thoracic Surgery, Weill-Cornell Medicine, New York-Presbyterian Hospital, New York, NY.

Disclosures: Dr Altorki receives clinical trial support from Astra-Zeneca LLC. Dr Stiles has speaker and advisory board roles for AstraZeneca, has a speaker role for Medtronic and WebMD, has an advisory board role for the Lung Cancer Research Foundation, reports spouse's ownership of Pfizer stock, and reports spouse's receipt of a salary from and ownership of stock in Pharmaceutical Product Development.

Received for publication Sept 6, 2019; revisions received Sept 6, 2019; accepted for publication Sept 10, 2019; available ahead of print Sept 20, 2019.

Address for reprints: Nasser Altorki, MD, Division of Thoracic Surgery, Weill-Cornell Medicine, New YorkPresbyterian Hospital, 525 E 68th St, New York, NY 10023 (E-mail: nkaltork@med.cornell.edu).

J Thorac Cardiovasc Surg 2020;160:1346-7

0022-5223/\$36.00

Copyright $($ c 2019 by The American Association for Thoracic Surgery

https://doi.org/10.1016/j.jtcvs.2019.09.010
}

In Shakespeare's play The Tempest, Antonio says to his friend Sebastian, "What's past is prologue," meaning that what happened in the past is no longer relevant to the glorious future upon which they will soon embark. And so it should be with thoracic oncologists after nearly a quarter century of clinical trials of bimodality and trimodality therapy in patients with stage IIIA N2 non-small cell lung cancer (NSCLC). So, what have we learned from these trials? Well, we learned that although preoperative chemoradiation leads to higher rates of nodal downstaging and complete pathologic responses, improvements in survival beyond those achievable by preoperative chemotherapy alone remain insanely elusive. Most disturbingly, trimodality therapy appears to be associated with significantly higher mortality after complex resections such as pneumonectomy and bilobectomy, which may be required in approximately $15 \%$ to $30 \%$ of patients with this stage of disease. Despite these concerns, first alluded to by the investigators of the intergroup trial, ${ }^{1}$ the concept put forward was that even higher doses of radiation would further increase the rate of nodal downstaging and that a stricter control of surgical quality would avert higher perioperative mortality. The report by Donington and colleagues $^{2}$ in this issue of the Journal is a timely and valuable contribution and sheds necessary clarity about what can be expected when operating on patients treated by preoperative high dose radiation and chemotherapy. Donington and colleagues ${ }^{2}$ pooled the perioperative outcomes of patients enrolled in 2 trials, RTOG 0229 and 0839 , undertaken primarily to examine the effects of including definitive doses of radiation $(60 \mathrm{~Gy}$ and 61.2 Gy) with chemotherapy in a neoadjuvant setting on mediastinal nodal downstaging. What is compelling to us is the finding that after high-dose induction chemoradiation, lobar resection could be safely performed with $30-$ and

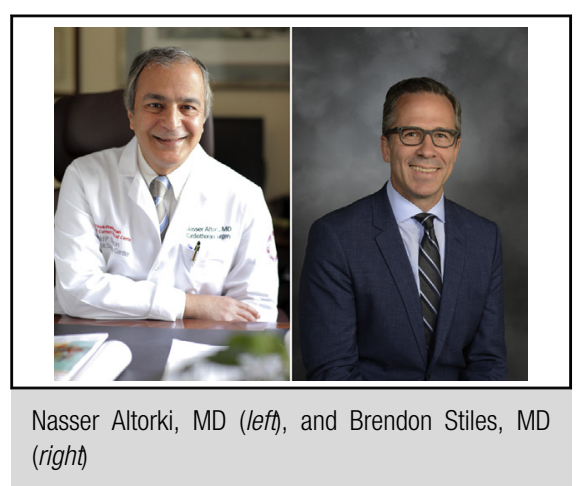

\section{Central Message}

Important data from 2 phase 2 trials with chemotherapy plus high-dose radiation before stage IIIA NSCLC surgery show that lobar resection can be done safely but complex resections carry $20 \%$ mortality.

See Article page 1331. 90-day mortalities of $1.3 \%$ and $2.6 \%$, respectively. Despite stricter surgical quality control, however, the mortality after complex resection remains stubbornly high at $19 \%$. To put these results in context, it is important to consider that despite the best efforts by the trial investigators, patient accrual for these 2 trials was painfully slow (4 to 5 years), and each center may have contributed fewer than 3 patients per year. What we also find compelling is that though much is ventured, little is gained. Notably, complete pathologic response $(25 \%)$ and mediastinal nodal downstaging are within the range expected after less intensive local therapy.

We would argue that perhaps the era of neoadjuvant trials with chemotherapy or radiation alone should be behind us. As seen in RTOG 0229 and 0839 , and previously in the Intergroup 0139, SAKK 16/00, and other trials, compete pathologic response rates greater than $25 \%$ to $30 \%$ and prolonged progression-free survival are unlikely to be obtained with standard trimodality therapy. ${ }^{1,3}$ Although extended resections, including pneumonectomy, could be justified given the high likelihood of persistent local disease after even definitive chemoradiation, the high rate of perioperative mortality reported here by Donington and colleagues $^{2}$ and previously by the Intergroup 0139 authors should give both surgeons and patients pause and reason to look for alternative strategies. Even in patients who survive the operative period after pneumonectomy, quality 
of life may suffer and poor performance status may limit the ability to receive future therapy, which is indicated more often than not, given the high rate of progression for these patients with a heavy disease burden.

With the prologue behind us, it is clearly time to move on to neoadjuvant immunotherapy trials for locally advanced NSCLC. The A Global Study to Assess the Effects of MEDI4736 Following Concurrent Chemoradiation in Patients With Stage III Unresectable Non-Small Cell Lung Cancer (PACIFIC) trial $^{4}$ has already demonstrated that adjuvant immunotherapy after chemoradiation improves outcomes of patients with unresectable stage III disease relative to chemoradiation alone. The outstanding survival seen to date in that trial raises the tantalizing possibility that we can do even better by including surgery for local control in patients with resectable disease. Numerous trials are already underway that use neoadjuvant immunotherapy, with major pathologic response rates reported to be $17 \%$ to $45 \%$ for single-agent immunotherapy. Given these early data, we are convinced that this is the way forward, particularly as we learn to predict more accurately which patients will respond to immunotherapy. We also feel that future trials exploring lower (rather than higher) doses of chemotherapy and radiation therapy as immune primers have a strong scientific rationale. Although we have much to learn, now is exactly the time to break new ground, and surgeons must be at the forefront of this endeavor.

\section{References}

1. Albain KS, Swann RS, Rusch VW, Turrisi AT III, Shepherd FA, Smith C, et al Radiotherapy plus chemotherapy with or without surgical resection for stage III non-small-cell lung cancer: a phase III randomised controlled trial. Lancet. 2009;374:379-86.

2. Donington JS, Rebecca R, Suntharalingam M, Loo B, Feigenberg SJ, Gregory EM et al; NRG Oncology. Resection following concurrent chemotherapy and high-dose radiation for stage IIIA non-small cell lung cancer. J Thorac Cardiovasc Surg. 2020;160:1331-45.e1.

3. Pless M, Stupp R, Ris HB, Stahel RA, Weder W, Thierstein S, et al; SAKK Lung Cancer Project Group. Induction chemoradiation in stage IIIA/N2 non-small-cell lung cancer: a phase 3 randomised trial. Lancet. 2015;386: 1049-56.

4. Antonia SJ, Villegas A, Daniel D, Vicente D, Murakami S, Hui R, et al; PACIFIC Investigators. Overall survival with durvalumab after chemoradiotherapy in stage III NSCLC. $N$ Engl J Med. 2018;379:2342-50. 